\title{
Canada publishes more equivocal evidence
}

\section{Washington}

CANADIAN studies of yellow rain samples published last week by the Canadian Defense Research Establishment are being claimed as support both by those who believe the phenomenon to be due to chemical warfare and those who believe it to be merely mass defecation by bees. The study* finds small amounts of tricothecene toxins in some of the samples collected by Canadian military medical teams from Thailand in 1982, but notes that the levels are similar to those found in stored cereals infected with Fusarium fungus and concludes that "it is difficult to say if there is any chemical warfare significance".

Supporters of the US government's claim that tricothecene toxins have been used by Vietnamese and Laotian forces against civilians are, however, more impressed by higher levels of tricothecenes found on a plastic bag handed to the Canadian team by a villager from $\mathrm{Ban} \mathrm{Sa}$ Tong which they believe could be part of a toxic weapon.

In the Ban Sa Tong incident, which occurred on 19 February 1982, villagers reported that an aircraft circled the village at 5,000 feet before releasing yellow rain. As most of it fell on just six houses, supporters of the weapon theory have had to sup-

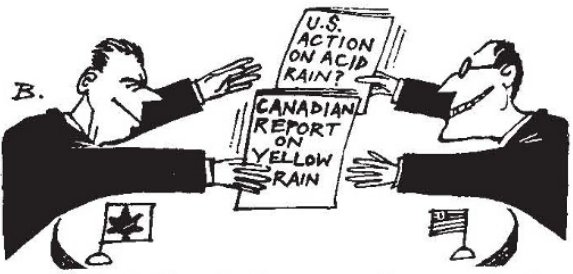

pose that the toxin was dispersed at a much lower level. Evidence of a dispersion device has so far been lacking, yet William Kucewicz of the Wall Street Journal's editorial board wrote on 31 March that the Canadian report provided "the most conclusive proof yet that yellow rain is a man-made weapon" and that it "rules out the possibility these particular mycotoxins were naturally occurring".

Kucewicz's article, which appeared be-

\section{Yellow rain}

\section{British assays negative}

THE Wall Street Journal article that has incensed the Canadians also referred to measurements made by British laboratories, which are said to have confirmed the presence of tricothecenes in samples of vegetation from South-East Asia, provided from the United States. But even though the results of the British measurements, carried out at the Chemical Defence Research Establishment of the British Ministry of Defence, are known to have been negative and not positive, the British authorities have not yet reacted with matching indignation at the Journal's misrepresentation.

The British experiments were carried out with great care, after the difficulties of the analysis of natural samples for quantities of tricothecenes of the order of parts per billion had been fully assessed. The work occupied a period of several months during 1983 , and cost some $£ 100,000$. The negative results have been reported to the US defence laboratories involved in the analysis. There was an opportunity for a formal comparison of the results obtained at half a dozen laboratories, mostly in the United States, at a private symposium last year after a Gordon conference on tricothecenes held in New Hampshire.

Since the significance of the British measurements became apparent to the
British authorities, there has been a careful evaluation of the manner in which they were carried out. This, however, has not shaken the confidence of those responsible for the measurements or of their managers in the general conclusion that the samples from South-East Asia embody no decisive evidence that yellow rain is linked with artificially engendered tricothecene toxins.

The Wall Street Journal has had an extreme position on the supposed Soviet use of chemical weapons for at least the past two years. In 1983, William Kucewicz published a series of articles in the Journal which, among other things, alleged that Soviet laboratories were using genetic manipulation to manufacture influenza viruses that could be used as biological warfare agents. Last year, he published a fierce attack on Professor Matthew Meselson of Harvard University after the latter had published an account of his bee faeces theory in Scientific American.

A formal report of the British measurements is believed to have been circulated among British government departments. A spokesman for the Ministry of Defence said earlier this week that investigations were continuing, and that it was the present intention to publish the results.

John Maddox fore the report was published, has prompted the Canadian government to express concern about misrepresentation of the report to the US government - the apparent source of the "essential details" leaked to Kucewicz. The Canadian Ambassador has written to the Journal and to a Thai newspaper that reprinted Kucewicz's article saying the report "does not reach conclusions" on possible use of toxic weapons.

All the plant samples examined by the Canadians proved to consist mainly of pollen, consistent with the hypothesis of Matthew Meselson of Harvard University that the characteristic yellow spots found on leaves result from mass defecations by bees, a well-recognized phenomenon. Where tricothecenes were present, they were generally only just distinguishable from background noise by gas chromatography and mass spectrometry. The report notes that, since little is known about the natural occurrence of tricothecenes in South-East Asia, comparisons with natural levels and types are "difficult if not impossible". None of the biomedical samples from exposed villagers discussed in the report showed evidence of tricothecenes, and there were no deaths caused, although an earlier Canadian study found an increase in cold-like symptoms.

The bag, in contrast - torn and dusted with a brown powder - did not contain pollen, although the Canadians did not apparently analyse the dust completely. The report is properly circumspect about the provenance of the bag, which unlike other samples was not collected by the Canadians at first hand but was offered by a villager some weeks after the 19 February incident, during a follow-up visit. Meselson argues that a bag used as part of a delivery system would have been found sooner during the intensive investigations and that it might be expected to show evidence of burn marks from explosives: whatever was on the bag could not be the same as "yellow rain" because of the absence of pollen. The levels of toxin found on the bag (one analysis showed 230 p.p.m. of T-2 toxin in the dust, although a later check found only 6 p.p.m.) are not inconsistent with a natural origin; in the laboratory, 900 p.p.m. of T-2 have been obtained in barley infected with Fusarium.

Meselson says the Canadians have presented the best-ever documented case of bee defecation but complains that the "rather pathetic analysis" of the plastic bag fails to provide sufficient information to know what absolute quantities of toxins were present. Meselson is sticking with bees for the later "yellow rain" reports, but does not exclude the possibility of some other chemical weapons having been used in Cambodia during the late 1970s.

Tim Beardsley

"Final Summary Report on the Investigation of "Yellow Rain" Samples from South-East Asia. 